Further, the Modern Matron is working to build nursing teams' confidence in taking appropriate risk to enable improved patient outcomes.

Conclusion The interview indicates that using clinical leadership skills to create tangible links between strategy and day-today practice, and bridging care between hospital and community are key priorities for the Modern Matron for Palliative and End of Life Care role. The impact will be explored further in a future evaluation of the wider partnership.

\section{P-224 THE VALUE OF HOSPICES IN NORTH WALES A COLLABORATION BETWEEN ACADEMIA AND THIRD SECTOR ORGANISATIONS}

${ }^{1}$ Nicole Hughes, 'Jane Noyes, ${ }^{1}$ Carys Jones, ${ }^{2}$ Trystan Pritchard. 'Bangor University, Bangor, UK; 'St David's Hospice, Llandudno, UK

10.1136/bmjspcare-2018-hospiceabs.249

Background In a difficult financial climate, hospices need to reaffirm their impact and contribution to society. Evaluating the externalities associated with the hospice services provided and alternative models of care will inform resource allocation. This partial economic analysis is being undertaken as a component of a larger study utilising a Social Return on Investment framework (SROI) to investigate the social, economic and environmental impact of hospice services.

Aim The aim is twofold; to estimate the costs per inpatient bed day for those nearing end of life to inform an analysis of how patient disease and health system related factors influence resource allocation and costs. Secondly, to demonstrate how the costs associated with the day care and inpatient units differ across alternative models of care.

Method A partial economic analysis will be performed as part of a multi-site comparative study of four hospices across North Wales, with the focus placed on the inpatient and day care units. Anonymised patient level data from each hospice will be accessed retrospectively and used in conjunction with the hospices' annual accounts for October 2016. Hospice costs will be estimated using a bottom-up approach which will demonstrate the use of detailed activity and input usage data from records at the service provider level to estimate unit costs. This approach will also help to capture the site level differences.

Results The results are pending as the study is still being undertaken at time of abstract submission.

\section{P-225 ENABLING COMPREHENSIVE PERSON-CENTRED SUPPORT FOR FAMILY CARERS OF PEOPLE WITH MOTOR NEURONE DISEASE}

${ }^{1}$ Gail Ewing, ${ }^{2}$ Sarah Croke, ${ }^{2}$ Christine Rowland, ${ }^{2}$ Gunn Grande. ' University of Cambridge, Cambridge, UK; ${ }^{2}$ University of Manchester, Manchester, UK

\subsection{6/bmjspcare-2018-hospiceabs. 250}

Background Motor Neurone Disease (MND) is a life-shortening condition with no cure. Consequently, hospice and palliative care are recommended from diagnosis. Family carers provide vital support for people with MND but caregiving can be very physically and mentally demanding. It is therefore crucial to ensure healthcare practitioners (HCPs) can provide timely support to carers fitting their individual needs. Currently there are no UK interventions for this.

Aim To adapt an existing Carer Support Needs Assessment Tool (CSNAT) intervention for comprehensive person-centred carer to support the needs and situation of family carers of people with MND.

Methods Stages:

1. Focus groups and interviews with 33 carers (14 bereaved, 19 current carers) to capture their self-defined needs, key points of change during patient's illness, and main support services.

2. Workshops with HCPs $(\mathrm{N}=22)$ and carer advisors $(\mathrm{N}=19)$ to inform materials and procedures for MND carer assessment and support.

Results Stage 1: Carers' experience was one of dealing with a devastating diagnosis, a constantly changing situation with heavy dependence on them as carers, and with little consideration of their separate support needs. Carers' support needs mainly mapped onto CSNAT domains, but some MND carers experienced relationship issues warranting further consideration. Stage 2 (on-going) will review carer advice on the need for a further CSNAT domain to address relationship issues; HCP and carers' views obtained at workshop discussions explore when, where, how and by whom MND carer assessment and support should best be provided in a practice context.

Conclusions Study findings will provide insights into how MND carers want to be assessed and supported and how HCPs felt this approach could be delivered in practice. Understandings obtained from Stages 1 and 2 will form the basis for an intervention to be tested in a future Stage 3 feasibility study.

\section{The workforce and workplace}

\section{P-226 REVIEW OF A GP FELLOWSHIP SCHEME IN PALLIATIVE MEDICINE}

${ }^{1,2}$ Rebecca Thompson, ${ }^{1}$ Karen Chumbley, ${ }^{1,3}$ Jennie Stemp. 'St Helena Hospice, Colchester, UK; ${ }^{2}$ Ardleigh Surgery, Ardleigh, UK; ${ }^{3}$ Parsons Heath Medical Centre, Colchester, UK

\subsection{6/bmjspcare-2018-hospiceabs.251}

Background End of life care is a core part of General Practice yet there is often little formal palliative care training for GPs (Barclay, Todd, Lipscombe, 1997) emphasising the need for improved training and collaboration between Primary Care and Palliative Care services.

North East Essex with the support of the East of England Deanery established a Post CCT (certificate of completion of training) Fellowship Scheme offering education within a subspeciality. Two posts were created in specialist Palliative Medicine. Similar schemes have shown improvement in patient management (Duckett \&Casserly, 2003).

Aims

- Improve recruitment and retention of GPs within the local area (Marchand \& Peckham, 2017)

- Improve palliative care expertise in Primary care (Mitchell, 2002)

- GP development and education (Shipman, Addington-Hall, Barclay et al., 2001)

- Promote collaborative working between Primary care and Palliative Medicine. 
Methods The Post CCT Fellowship scheme was advertised online as an innovative attempt to improve recruitment and collaborative working between primary and secondary care.

Results Two newly qualified GPs were recruited. Both GPs were employed in a local GP practice and worked one session a week at the hospice. The scheme provided funding for postgraduate education. One GP has completed a Postgraduate Diploma in Palliative Medicine and the other has completed the Postgraduate Certificate in Palliative Medicine. The roles have covered inpatient and community palliative care. The collaboration has supported the hospice strategy of addressing inequity in palliative care access for people with dementia and heart failure. One GP has taken a leading role towards improving primary care training and education.

Conclusions The GP Fellowship Programme has improved patient management for patients within North East Essex and enhanced GP development. These skills will be cascaded to GP colleagues via a GP Community of Practice and formal GP education. Both posts have led to successful permanent recruitment in local primary care.

\section{P-227 STIMULATION THROUGH SIMULATION}

Angie Pymm. Isabel Hospice, Welwyn Garden City, UK

10.1136/bmjspcare-2018-hospiceabs.252

Can the use of a mannequin help hospice nurses retain competence in seldom used clinical skills?

Background Simulation is widely used to teach healthcare professionals end of life care communication skills (Smith, Tamara, Macierira et al., 2018, cites 30 such studies) and the use of simulation is becoming commonplace in undergraduate nurse programmes (Warren, Luctkar-Flude, Godfrey et al., 2016; Cant \& Cooper, 2017). However, little research has been carried out into the retention of seldom used clinical skills by nurses working in a hospice inpatient unit (IPU). Anecdotal evidence suggests that it is often difficult for IPU nurses to achieve and retain some clinical skills, including administering IV therapies, tracheostomy care, PEG management, stoma care and catheterisation.

Aim To enable IPU nurses to attain/retain some key clinical skills, thereby increasing their confidence and improving the care they are able to offer to patients.

Methods Registered nurse competencies will be reviewed in June 2018 to establish who is within timeframe for competence achievement/retention. A planned programme incorporating theory and practical sessions with the mannequin for the clinical skills listed above will be delivered between June and December 2018. Competencies will be re-reviewed in December 2018 .

Results It is anticipated that all nurses will have completed competencies in the listed skills by 1 January 2019. A rolling programme can then be put in place to ensure retention of skills.

Conclusion Patients have a right to expect optimal care. Nurses are mandated to be competent and confident in the clinical skills utilised in achieving that care. The use of a clinical skills mannequin may be a way of achieving and retaining that competence and confidence in seldom used skills, and hence may be instrumental in achieving optimal patient care.

\section{P-228 SO MUCH MORE THAN JUST A CHARITY SHOP?}

Becky McGregor. Mountbatten, Isle of Wight, UK

\subsection{6/bmispcare-2018-hospiceabs.253}

Introduction Are hospice charity shops more than just an outlet for 'charity goods sold at a profit but which aid beneficiaries' (Bruce, 2016) and utilised as a 'function as a way of raising awareness of the parent charity' (Charity Retail Association, 2017)?

Aim The aim of the study was to evaluate implementation of a new charity shop model. The concept was one that moved the charity shop from being a 'market follower' to being a 'market nicher' (Bruce, 2017) - one that has a competitive edge in the business and moral sense, by offering something distinctive and unique from the many charity shops found in the local area.

Approach used A new charity shop was opened by the hospice in January 2018. As well as being able to shop for secondhand items in order to raise vital funds for the charity, the new shop also offers a bespoke information area with free internet access, as well as a small café where the local community can meet together socially. The vision behind the shop is one based on the relationship marketing approach.

A pilot printed questionnaire was devised using the principles of effective market research questionnaire design (Sargeant \& Jay, 2014). The questionnaire was piloted in the charity shop during the first month of opening. Market research is perhaps the most important way of strengthening relationships' (Bruce, 2016).

Results A total of 50 questionnaires were distributed in the shop with a $76 \%$ response rate achieved. The results provide an understanding of the profile, needs and perspectives, giving an interesting insight into charity shop customers.

Conclusion It is but the start of a journey into development of a unique model of charity shop rooted in the core values of the charity, which demands further evaluation.

\section{P-229 THE DILEMMA OF MAKING BOLD BRANDING DECISIONS IN THE CHANGING WORLD OF PALLIATIVE CARE}

Claire Marshall. Compton Care, Wolverhampton, UK

10.1136/bmjspcare-2018-hospiceabs.254

When is a hospice not a hospice? The dilemma of making bold branding decisions in the changing world of palliative care.

Background and aims Exploring the journey of one organisation and how it made the boldest decision of its history to remove the word Hospice from its identity; what inspired the transformation, the process that was undertaken and the opportunities and the pitfalls facing similar organisations considering a radical change of brand.

Following a perception study which highlighted significant misconceptions of the organisation's brand and services, the transformation that followed set out to dispel long held myths about hospices and improve early referral rates, dispel fears about services and widen the reach for improved income generation.

Methods and results A perception study with a wide cross section of stakeholders was conducted to provide a platform for 